\title{
An analysis of the active safety of a passenger car body during car use
}

\author{
Jarosław Gonera ${ }^{1, *}$ and Jerzy Napiórkowski ${ }^{1}$ \\ ${ }^{1}$ Department of Design and Operation of Vehicles and Machines, University of Warmia and Mazury \\ in Olsztyn
}

\begin{abstract}
Passenger car bodies made nowadays are most often selfbearing constructions. This is the reason why a change in the parameters of a car body during its use also affects other sets of component parts, which are attached to it. While a passenger car is driven, the car body is exposed to various factors which can cause sudden damage or gradual wear of the car's technical condition. This paper contains an analysis of the influence of changes in the geometry of a car body on changes in the geometry of wheels. The study was carried out on C-segment cars produced by the same manufacturer. While making an assessment of the car body's geometry, the location of base points on the floor pan and the upper parts of the car bodywork, within the motor chamber, etc. was assayed. All vehicles were constructed on the same floor pan. Measurements were performed with a Gysmeter made by the company Gys and supported by Autorobot Datasheet software, while the geometry of wheels was measured with a computerised laser device Autoboss A-860. Camber, castor and steering axis inclination were some of the wheel geometry parameters measured in our study.
\end{abstract}

\section{Introduction}

Mandatory periodical inspections of the technical condition of passenger cars do not necessitate any detailed assessment of the technical condition in terms of the car bodywork geometry and wheel alignment [13]. Assessment of the car body geometry is made only in cars that have been engaged in road collisions and crashes. During mandatory periodical inspection, a mechanic only briefly inspects the basic elements of the car body's bearing structure, to verify that they are not damaged and do not impair the road traffic safety [15, $16,17,18]$. During the useful life of a passenger car, the automobile does not undergo periodical, multi-step investigations of the geometry of its bodywork [1]. The geometry of wheels is only measured after damaged or worn elements of the suspension system or the steering wheel system have been replaced. It is observed that quite many cars currently on our roads have been involved in various accidents or collisions, which invariably cause some damage to the car body $[8,11]$. There are no detailed studies which would describe dependences between the scope of bodywork repairs and the technical condition of the systems responsible for the vehicle's safe use $[5,8,14]$.

The use of elements connected with the active and passive safety in passenger cars contributes significantly to protecting the driver or passengers and other road users $[9,10]$. Costs incurred by adding safety-enhancing elements are disproportionately low compared to the costs of removing consequences of an accident [3]. While constructing a vehicle, manufacturers follow two directions in the development of systems responsible for safety: reducing the risk of a traffic accident (active safety) and reducing injuries during an accident (passive safety) $[4,7]$.

\footnotetext{
*Corresponding author: jaroslaw.gonera@uwm.edu.pl
} 


\section{Problems associated with measurements of the car bodywork geometry and wheel geometry}

There is a set of base points on a floor pan and in the upper parts of a body of any passenger car. Their location is determined by the car manufacturer. These points are typically construction holes, which help fix subunits of a vehicle, and auxiliary holes, made specially for measuring geometry [1]. The location of base points is illustrated in charts issued for mechanical measurement tools and in software databases develop to support electronic devices. When making measurements of the geometry of a car body, the required position of base points is compared with their actual location, which is determined through measurements [12]. Measurements of the geometry of a car body are made both in the area of the floor pan and in the upper parts of the body. For the sake of such investigations, it is presumed that the maximum difference between the required and actual location of base points must not exceed $3 \mathrm{~mm}[1,11]$.

The geometry of the body is directly connected with the geometry of the suspension and steering systems. The reason is the fact that components of the suspension system and steering system are mounted onto the body. The moment the base points responsible for fixing these elements is shifted on the body, the parameters related to setting the wheels (their geometry) will change, too. The most important parameters associated with the geometry of wheels and affecting the way a car is driven are: front and rear axle toe, front and rear axle camber, values of the steering axis castor, steering axis inclination angles, deviation of the driving axis from the axis of symmetry, wheelbase difference, front and rear axle wheel setback $[5,11,14]$.

Many of the parameters connected with the geometry of the suspension system and steering wheel system in most of the passenger cars manufactured nowadays cannot be regulated. Often it is impossible to adjust, for example, wheel camber, steering axis inclination or the angle of castor. Whenever certain irregularities are detected in this respect, it is necessary to repair the car bodywork, as the proper geometry of the suspension and steering systems cannot be restored unless the geometry of the car body is restored first $[6,13,14]$.

\section{Research methodology}

The study included 10 passenger cars manufactured by the same motor vehicle maker. All the cars belonged to the C-segment according to the European classification systems. They were equipped with a MacPherson's strut and a semi-float rear axle suspension with a torsion beam. In addition, they had a rack and pinion steering system. The cars had been produced 12 to 14 years before the tests, and they had a mileage of 250000 to $350000 \mathrm{~km}$. All had been driven on roads in Poland only. None had been in a car crash or collision.

A Gysmeter made by Gys (fig. 1) was used to measure the geometry of the car bodies. This is an electronic, telescope device used for measuring the geometry of a floor pan and upper elements of a car shell. It is not necessary to disassemble any of the elements of a car in order to make measurements with this tool. The accuracy of measurements taken with a Gysmeter was $1 \mathrm{~mm}$, while the measurement range was within 400 to $2650 \mathrm{~mm}$. During the measurements of the car body geometry, the position of base points located on the floor pan and upper parts of the bodywork was analysed. The information about the obligatory location of base points was derived from the database of the software named Autorobot Data System. 




Fig. 1. Taking measurements of the geometry of a floor pan with a GYSMETER by GYS.

Measurements of the floor pan geometry and upper body parts were carried out mainly at the points connected with the mounting of the front suspension, the rear suspension and the front bench. These points were selected because they directly affect the position (geometry) of the suspension system and steering system. In addition, the displacement of the base points located on the front and rear frame rails and in the vicinity of the bulkhead was determined. During the measurements, the position of all analysed points relative to the initial ones, which were found in the rear part of the passenger compartment, were analysed. In none of the analysed cars, changes in the geometry of the floor pan were observed with respect to this aspect. The analysed sites in a car are illustrated in figs. 2 and 3.



Fig. 2. A view of the floor pan originating from the Autorobot Data System programme, where $1-$ points lying on the front railsm 2 - points fixing the front suspension, 3 - points fixing the front bench, 4 - points located in the vicinity of the bulkhead, 5 - points fixing the rear suspension, $6-$ points located on the rear rails. 



Fig. 3. A view of the upper bodywork parts (the motor chamber) plotted in an Autorobot Data System programme, where $\mathrm{McPh}$ - mounting of a MacPherson's strut.

The measurements of the geometry of the suspension and steering systems were carried out using an Autoboss A860 device. It is a computerised laser device for measuring practically all parameters connected with the geometry of wheels. It was equipped with a special programme and four heads, which were mounted on individual wheels of a car during the measurements. The communication between the heads and between each head and the steering unit was remote. The resolution for all measurements was $1^{\prime}$. The instrument enabled the user to measure the geometry of cars having wheels with a diameter from 11 " to 21 ". As a result of the wheel geometry measurements, the parameters shown in Figure 4 were determined.

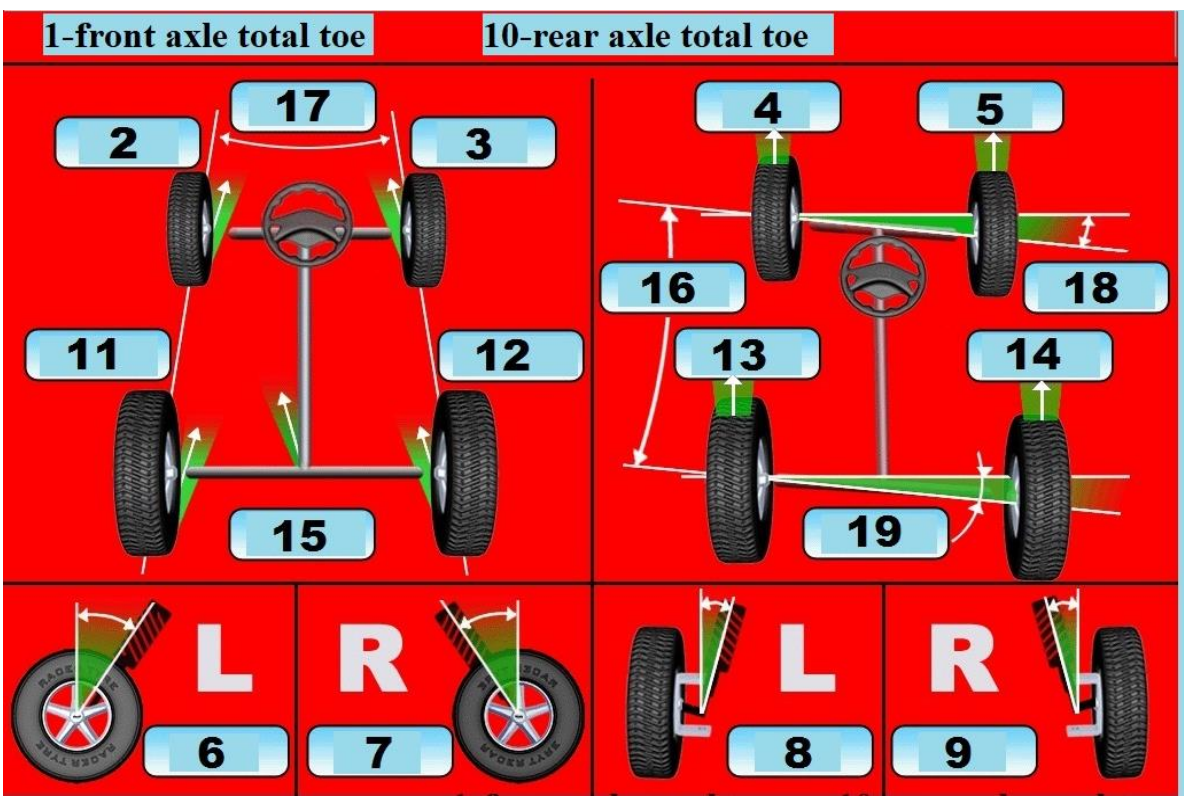

Fig. 4. Wheel geometry parameters, where: 1-front axle total toe; 2 -front axle left wheel toe; 3 -front axle right wheel toe; 4-front axle left wheel camber; 5-front axle right wheel camber; 6-front axle left wheel castor; 7-front axle right wheel castor; 8- steering axis inclination for the front axle left wheel; 9- steering axis inclination for the front axle right wheel; 10-rear axle total toe; 11-rear axle left wheel toe; 12-rear axle righ wheel toe; 13-rear axle left wheel camber; 14-rear axle right wheel camber; 15driving axis from symmetry axis deviation; 16-wheelbase difference; 17-track width difference; 18 setback (front axle); 19-setback (rear axle). 


\section{Results of measurements of the car bodywork geometry}

Based on the results (Tab. 1), it can be concluded that the smallest alterations in the geometry of a car body were noted in the vicinity of the bulkhead. In this area, the displacement of base points was no more than $1 \mathrm{~mm}$. As for the points located on rear rails, the shift of the base points in most cars did not exceed $3 \mathrm{~mm}$. However, this difference in 1 car was larger, around $11 \mathrm{~mm}$. Changes in the geometry measured on front rails were usually within a range of 0 to $5 \mathrm{~m}$, and in one case reached $7 \mathrm{~mm}$. Larger differences were observed in the other areas of car bodies analysed, for example differences between the required and actual location of base points mounting the front suspension were within an interval of 2 to $31 \mathrm{~mm}$. In turn, for points fixing the front bench the respective differences fell within the range of 2 to $9 \mathrm{~mm}$. Points mounting the rear suspension were displaced from 1 to $6 \mathrm{~mm}$. Considerable changes in the geometry were also determined in the motor chamber. With respect to the points representing the upper fixing of MacPherson's struts, the differences ranged from 3 to as much as $16 \mathrm{~mm}$.

Tab. 1. Results of measurements of the geometry of the car body in the analysed vehicles.

\begin{tabular}{|c|c|c|c|c|c|c|c|c|c|c|c|c|}
\hline \multicolumn{2}{|c|}{ No of car } & S1 & S2 & S3 & S4 & S5 & S6 & S7 & S8 & S9 & S10 & \multirow{2}{*}{$\begin{array}{l}\text { Value of } \\
\text { the shift of } \\
\text { a given } \\
\text { base point } \\
\text { [mm] }\end{array}$} \\
\hline \multicolumn{2}{|c|}{ Base point } & \multicolumn{10}{|c|}{ Value of the shift of a given base point [mm] } & \\
\hline $1 \mathbf{P}$ & \multirow{2}{*}{ Front rail } & 2 & 0 & 3 & 2 & 2 & 0 & -4 & 2 & 3 & -5 & 2,3 \\
\hline $1 \mathrm{~L}$ & & 0 & 1 & 5 & 2 & 2 & -4 & 3 & 2 & -5 & -7 & 3,1 \\
\hline $2 \mathbf{P}$ & \multirow{2}{*}{$\begin{array}{l}\text { Mounting of } \\
\text { the front } \\
\text { suspension }\end{array}$} & -7 & -8 & -4 & -9 & -7 & -8 & -11 & -7 & -11 & -31 & 10,3 \\
\hline $2 \mathrm{~L}$ & & -5 & -7 & 2 & -7 & 6 & -6 & -4 & -7 & -13 & -20 & 7,7 \\
\hline $3 \mathbf{P}$ & \multirow{2}{*}{$\begin{array}{c}\text { Mounting of } \\
\text { the front } \\
\text { bench }\end{array}$} & -6 & -2 & -3 & -6 & -5 & -7 & -7 & -6 & -7 & -9 & 5,8 \\
\hline $3 \mathrm{~L}$ & & -4 & 2 & 2 & -5 & 4 & -5 & -3 & -5 & -7 & -7 & 4,4 \\
\hline $4 P$ & \multirow{2}{*}{$\begin{array}{l}\text { Vicinity of } \\
\text { the bulkhead }\end{array}$} & 0 & 1 & 0 & 0 & 0 & 0 & -1 & 1 & 1 & -1 & 0,5 \\
\hline $4 \mathrm{~L}$ & & 1 & 0 & 0 & 0 & -1 & 0 & -1 & 0 & 1 & -1 & 0,5 \\
\hline 5P & \multirow{2}{*}{$\begin{array}{l}\text { Mounting of } \\
\text { the rear } \\
\text { suspension }\end{array}$} & 1 & 5 & 3 & -3 & 4 & 5 & 5 & 6 & -3 & 2 & 3,7 \\
\hline $5 \mathrm{~L}$ & & -4 & -4 & 5 & -4 & -4 & 2 & 3 & 4 & 5 & -6 & 4,1 \\
\hline $6 P$ & \multirow{2}{*}{ Rear rail } & 2 & 2 & 3 & 1 & -2 & 0 & 3 & 2 & 1 & -2 & 1,8 \\
\hline $6 \mathrm{~L}$ & & 1 & 2 & 2 & 0 & 1 & -1 & -2 & 11 & 3 & 3 & 2,6 \\
\hline McPh & $\begin{array}{l}\text { Top mounting } \\
\text { of a } \\
\text { MacPherson's } \\
\text { strut }\end{array}$ & -3 & -3 & -7 & -3 & -5 & -12 & -6 & -13 & -9 & -16 & 7,7 \\
\hline \multicolumn{2}{|c|}{$\begin{array}{l}\text { Average change in the } \\
\text { geometry in a car }\end{array}$} & 2,77 & 2,85 & 3,00 & 3,23 & 3,31 & 3,85 & 4,08 & 5,08 & 5,31 & 8,46 & \\
\hline
\end{tabular}

In order to determine the influence of the type and location of a base point on changes in the geometry of the floor pan and top mounting of MacPherson's struts, analysis of variance was applied (fig. 5). 


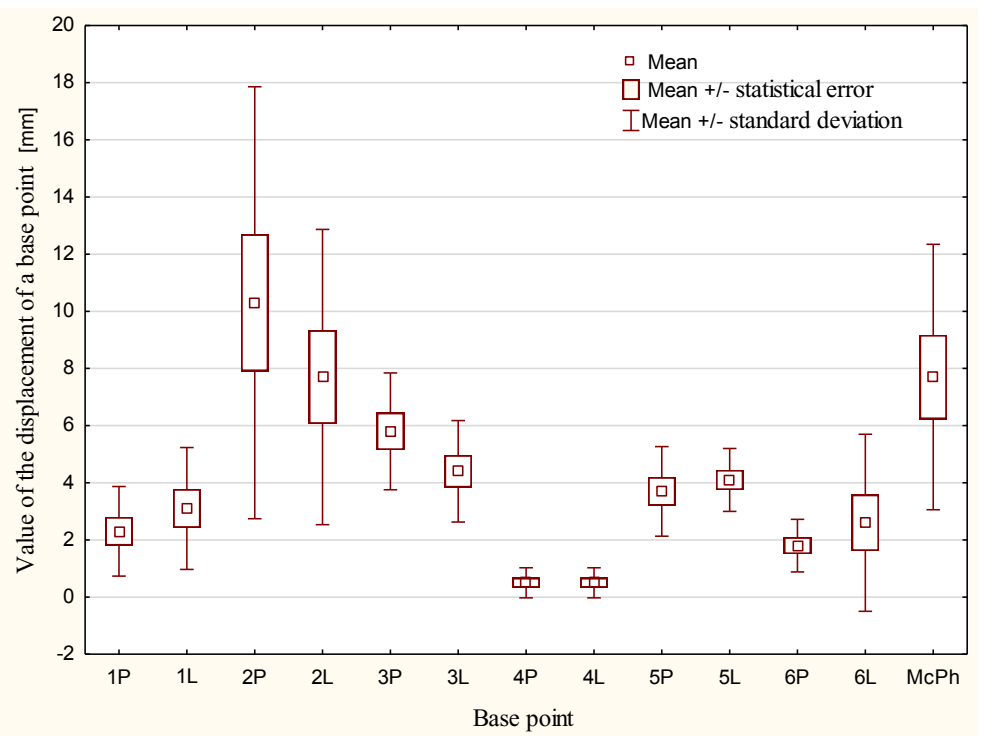

Fig. 5. Comparsion of changes in the geometry at particular base points on the floor pan and within the motor chamber.

A null hypothesis was formulated for each of the analysed points, suggesting the lack of differences between the values of changes in the geometry, as opposite to an alternative hypothesis stating significant differences in the geometry changes. Should the null hypothesis be rejected in favour of the alternative one, the Duncan test was used to distinguish homogeneous groups (Figure 6).

\begin{tabular}{|c|c|c|c|c|c|c|c|}
\hline \multirow{2}{*}{ No of subclass } & \multicolumn{7}{|c|}{ Duncan's test: alpha $=0,05000$} \\
\hline & No of base point & Means & 1 & 2 & 3 & 4 & 5 \\
\hline 8 & 4L & 0,5 & $* * * *$ & & & & \\
\hline 7 & $4 \mathrm{P}$ & 0,5 & $* * * *$ & & & & \\
\hline 11 & $6 \mathrm{P}$ & 1,8 & $* * * *$ & $* * * *$ & & & \\
\hline 1 & $1 \mathrm{P}$ & 2,3 & $* * * *$ & $* * * *$ & & & \\
\hline 12 & $6 \mathrm{~L}$ & 2,6 & $* * * *$ & $* * * *$ & $* * * *$ & & \\
\hline 2 & $1 \mathrm{~L}$ & 3,1 & $* * * *$ & $* * * *$ & $* * * *$ & & \\
\hline 9 & $5 \mathrm{P}$ & 3,7 & $* * * *$ & $* * * *$ & $* * * *$ & & \\
\hline 10 & $5 \mathrm{~L}$ & 4,1 & & $* * * *$ & $* * * *$ & & \\
\hline 6 & 3L & 4,4 & & $* * * *$ & $* * * *$ & & \\
\hline 5 & 3P & 5,8 & & & $* * * *$ & $* * * *$ & \\
\hline 13 & $\mathrm{McPh}$ & 7,7 & & & & $* * * *$ & $* * * *$ \\
\hline 4 & 2L & 7,7 & & & & $* * * *$ & $* * * *$ \\
\hline 3 & 2P & 10,3 & & & & & $* * * *$ \\
\hline
\end{tabular}

where ${ }^{\star \star \star \star}$ - illustrates statistically significant differences at $p<0.05$ between changes in

Fig. 6. The Duncan's test statistics regarding detailed differences between mean values of changes in the geometry of the car body.

The data presented above justify the conclusion that there are significant differences between individual points for which measurements were taken. Particularly large displacements were noted for the mounting points of the front suspension, which are the upper fixing of the MacPherson's struts. Big geometry changes were also visible for the fixing points of the front bench and the rear suspension. 


\section{Results of measurements of the geometry of wheels}

Table 2 presents the values of changes in the wheel geometry parameters. These changes were related to all parameters describing the geometry of the suspension and the steering systems. For many of these parameters, the measured values significantly exceeded the values of an acceptable change. In the cars tested, the only wheel alignment parameter that can be adjusted is the front axle toe. The other parameters cannot be regulated. The biggest changes, far above the acceptable ones, appeared in the steering axis inclination angle (fig. 6 ), for both the right and the left wheel on the front axle. Comparably large changes were also found in the geometry of the rear axle wheels. In this case, big changes were detected in many cars concerning both the camber and the toe values for each of these wheels.

Tab. 2. Values of changes in the parameters of the geometry of wheels in the analysed cars.

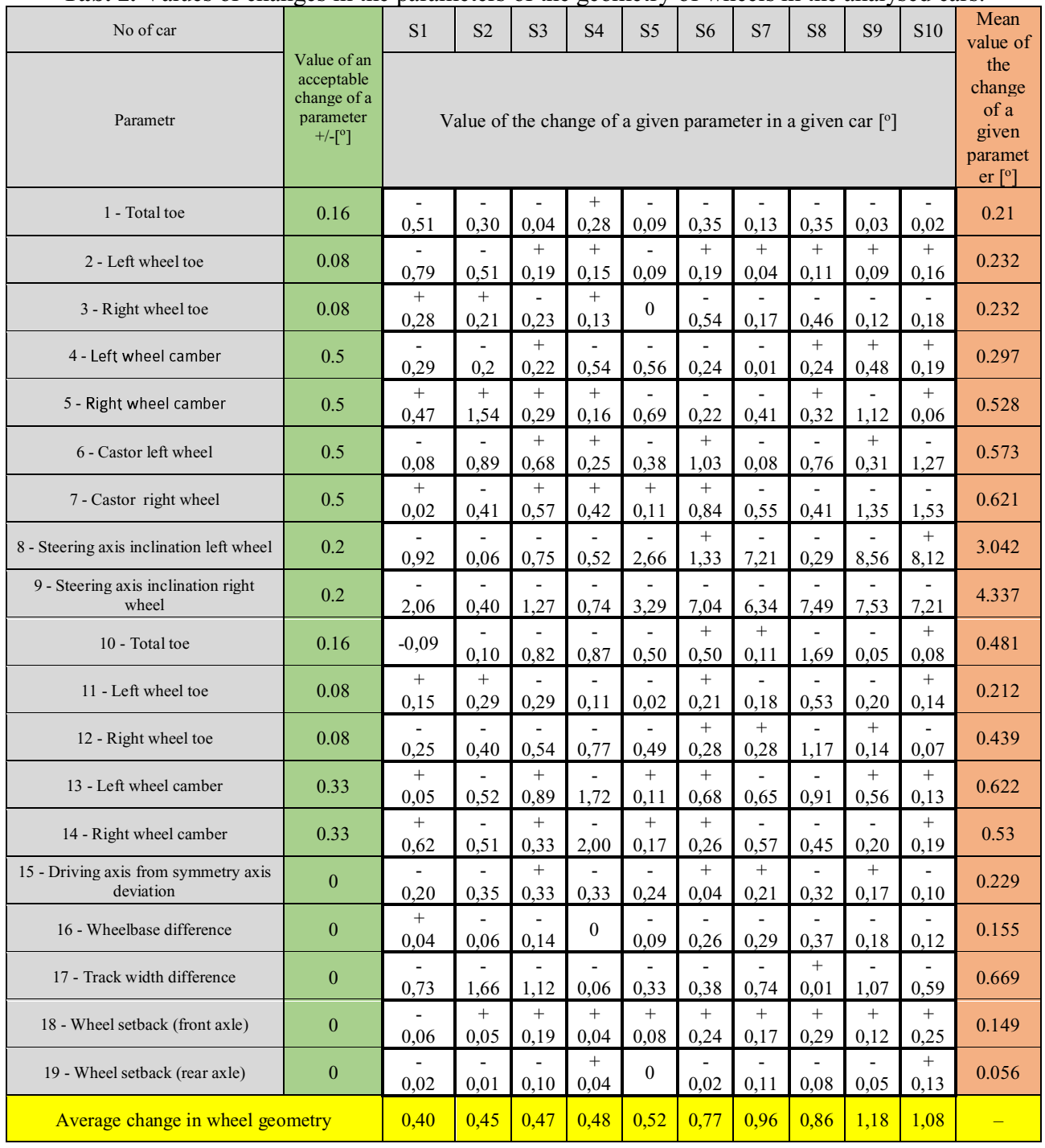




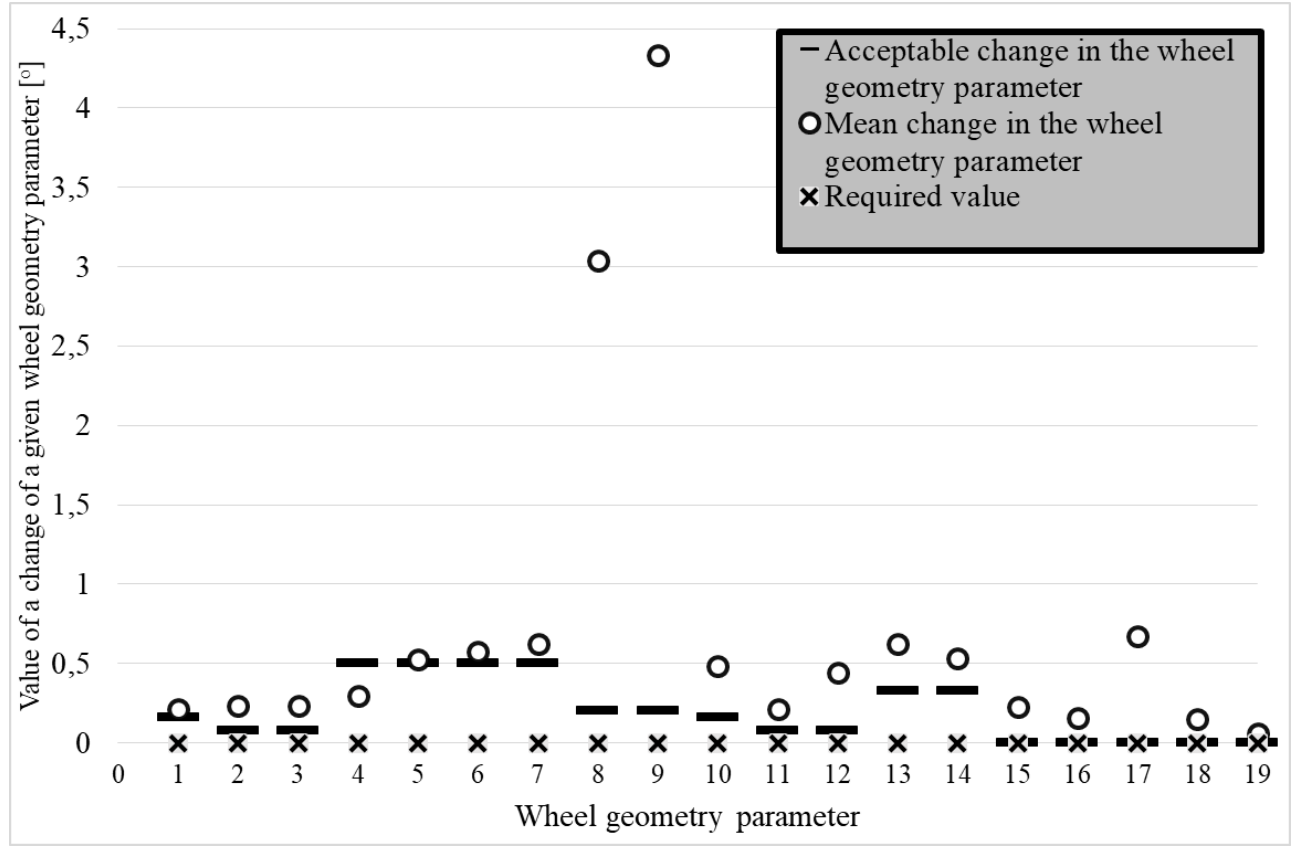

Fig. 6. Specification of changes in the wheel geometry parameters.

In order to determine the influence of the type of a wheel geometry parameter on changes in the geometry of the suspension system and steering system, analysis of variance was applied (fig. 7). A null hypothesis was adopted For each of the analysed points claiming that there was a lack of differences between the values of changes in geometry changes, and an alternative hypothesis suggesting the occurrence of significant differences in changes in geometry. It was found that the values of changes determined for the analysed parameters exceeded the thresholds. The biggest changes appeared for the parameters: the front axle left (8) and right (9) wheel camber.



Fig. 7. Diagram of changes in the geometry for particular wheel geometry parameters. 
Figure 8 illustrates the impact of changes in the car body geometry on changes in the wheel alignment. It appears that as changes in body geometry grow larger, changes in the wheel geometry increase as well, compared to standard values. In one case, a collapse of the geometry curve (fig. 10) was associated with the direction of the steering axis inclination.

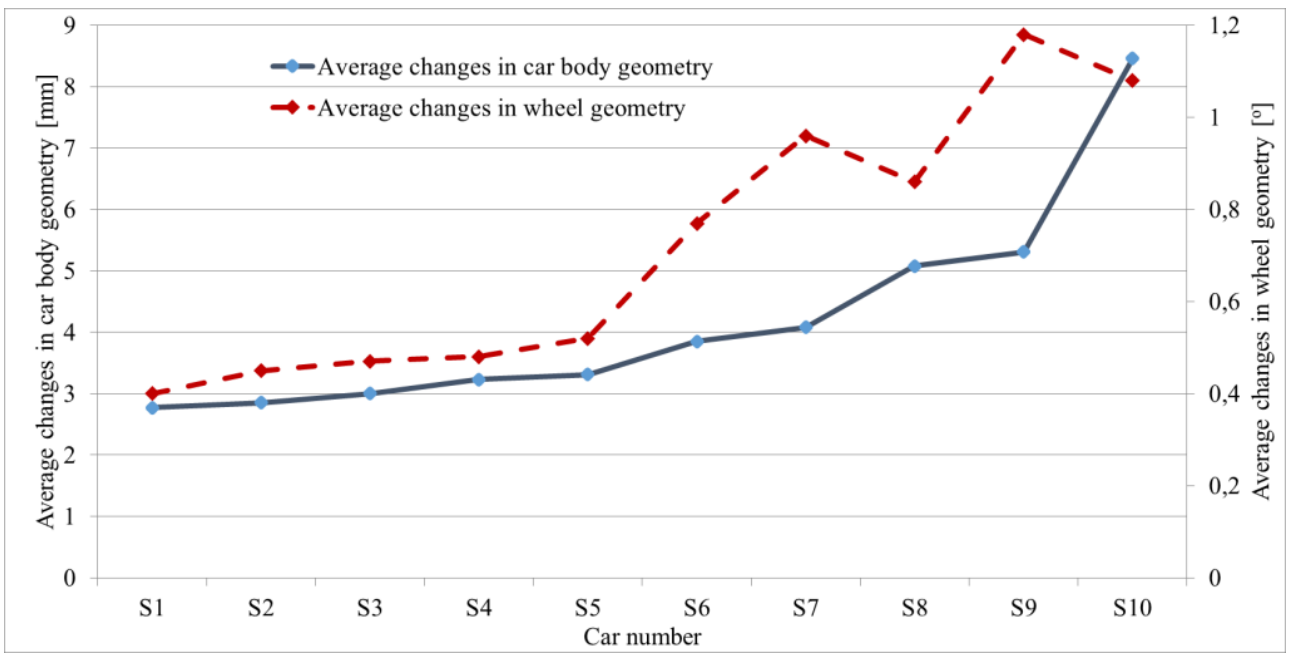

Fig. 8. Diagram of the influence of changes in the car body geometry on changes in the geometry of wheels.

\section{Conclusions}

The tested passenger cars, each with a mileage above $250,000 \mathrm{~km}$, significant changes were detected in the geometry of both the body and the suspension and steering systems. In either case, the changes demonstrated in most of the automobiles significantly exceeded the threshold values. It was found that larger changes in the body geometry tended to coincide with ap greater the changes in wheel alignment.

The biggest changes were determined for points mounting the front suspension (over $10 \mathrm{~mm}$ ) and representing the top mounting of the MacPherson's struts (around $8 \mathrm{~mm}$ ). Smaller changes appeared for the points mounting the front bench (ca $6 \mathrm{~mm}$ ) and rear suspension (over $4 \mathrm{~mm}$ ).

In turn, the biggest changes in the geometry of wheels appeared with respect to the steering axis inclination angle. A large change within this parameter was a consequence of the fact that it was under the influence of a large number of base points, i.e. points mounting the front bench, points being the top fixing of the MacPherson's strut as well as points mounting the front suspension. A shift of these base points also caused changes in the front wheel camber values. In some cars, changes in this parameter were thrice above the acceptable value. On the other hand, changes in castor were induced mainly by a change in the position of points mounting the front bench and the front suspension. In the case of this parameter as well, acceptable values were exceeded by as much as threefold. A change in the geometry of rear axle wheels was mostly caused by a shift of points fixing the torsion beam of the rear suspension. These points were displaced by different values on the left and on the right side of cars (a 10\% difference), which means that the beam was no longer set parallel to the transverse symmetry axis of the vehicle. In addition, displacement of individual base points fixing the front bench, front suspension and rear suspension by other values on the right and left side of the vehicle (difference by $30 \%$ ) caused differences in wheelbase between the left and right sides of the vehicle as well as differences in wheelbase 
between the front and rear axles (by as much as over 10), and a shift of wheels of the front axle and a shift of wheels of the rear axle.

\section{Bibliography}

1. J. J. Aguilar, M. Sanz, D. Guillomía, M. Lope, I. Bueno, International J. Adv. Man. T. 30, 1174 (2006)

2. R. Anderson, Division of Production and Materials Engineering (2007)

3. M. Berlemann, A. Matthes, Journal of Policy Modeling 36, 313 (2014)

4. H. Chen, X. Gong, Y. F. Hu, Q. F. Liu, B. Z. Gao, H. Y. Guo, Acta Autom. Sinica 39 (2013)

5. J. E. Duffy, Auto Body Repair Technology; Canada by Nelsin Education (2014)

6. J. Gonera, J. Napiórkowski, A. Olszewski, M. Janulin, Studies \& Proc. of Pol. As. of Kn. 79, 34 (2016)

7. A. Habibovic, J. Davidsson, Accident Analysis and Prevention 49, 493 (2012)

8. H. Huang, C. Li, Q. Zeng, Accident Analysis and Prevention 86, 129 (2016)

9. H. S. Kim, H. J. Kim, B. Bongsoo Son, Accident Analysis and Prevention 38, 981 (2006)

10. L. Laflamme, M. Vaez, M. Hasselberg, A. Kullgren, Safety Science 43, 1 (2005)

11. W. A. Livesey, A. Robinson, The repair of vehicle bodies (2006)

12. R. Michalski, J. Gonera, Studia i Materiały Pol. Stow. Zarz. Wied. 47, 169 (2011)

13. B. Raatz, Nowoczesne technologie pomiarów i napraw karoserii pow. (2005)

14. A. Tobota, Naprawy powypadkowe nadwozi, a bezpieczeństwo (1997)

15. Dziennik Ustaw RP Poz. 407 z dnia 25 marca 2013 r.

16. Dziennik Ustaw RP Poz. 776 z dnia 21 kwietnia 2015 r.

17. Dziennik Ustaw RP Poz. 1475 z dnia 24 sierpnia 2015 r.

18. Rozporządzenie Komisji (UE) nr 214/2014 z dnia 25 lutego 2014 r. 